\title{
st \\ Darwin e o colapso do projeto epistemológico fundacional moderno
}

\author{
Renan Springer de Freitas
}

\begin{abstract}
药
RESUMO

O colapso do projeto epistemológico fundacional do século xviı tem levado alguns autores a declarar que a epistemologia está morta. Tem havido, nas últimas décadas, um recuo em direção a uma abordagem pragmática do conhecimento, segundo a qual nada há a ser dito a respeito do conhecimento exceto o que possa vir a resultar de uma investigação sobre os modos como certas crenças se formam ou, alternativamente, um esforço, inspirado em Kant e em Heidegger, de superar a epistemologia via crítica das premissas antropológicas subjacentes ao anseio cartesiano por conhecimento apodítico. Dificilmente se percebe, entretanto, que Popper iniciou toda essa discussão sobre a pertinência do projeto epistemológico fundacional moderno sem, entretanto, decretar que qualquer projeto epistemológico concebível está necessariamente fadado ao fracasso. Ele vislumbrou uma solução no pensamento evolutivo darwiniano. Argumenta-se aqui que abordar o conhecimento à luz da evolução permite-nos evitar tanto o anseio por fundamentos últimos de validação do conhecimento, peculiar ao projeto epistemológico do século xviI, quanto a insustentável demanda, comum ao recuo pragmatista, tão em voga nos dias atuais, e ao esforço kantiano-heideggeriano de "superar a epistemologia", de que todo corpo de conhecimento seja confinado ao seu próprio tempo - ou, em outras palavras, de que o passado se torne irrelevante para o presente.
\end{abstract}

PaLAVRas-Ghave $\bullet$ Epistemologia fundacional. Recuo pragmatista. Pensamento evolutivo.

O colapso do projeto epistemológico fundacional do século xvıI tem levado alguns autores a declarar que a epistemologia está morta. Assiste-se, nas últimas décadas, a um recuo a uma abordagem pragmática do conhecimento, a qual postula nada haver a ser dito a respeito do conhecimento a não ser o que possa vir a resultar de uma investigação sobre os modos como certas crenças se formam ou, alternativamente, a um esforço, inspirado em Kant e em Heidegger, de superar a epistemologia via crítica das premissas antropológicas subjacentes ao anseio cartesiano por conhecimento apodítico. ${ }^{\mathbf{1}}$ Dificilmente se percebe, entretanto, que Popper iniciou toda essa discussão sobre a pertinência do projeto epistemológico fundacional moderno sem, entretanto,

1 "Overcoming epistemology" é, a propósito, o título de um trabalho de Charles Taylor, originalmente publicado em Bayes; Boham \& MacCarthy (orgs.), 1987 . 
decretar que qualquer projeto epistemológico concebível está necessariamente fadado ao fracasso. Ele vislumbrou uma solução no pensamento evolutivo darwiniano. O notável geneticista russo Theodosius Dobzhansky intitulou um de seus artigos: "Nada em biologia faz sentido exceto à luz da evolução”. ${ }^{2}$ Popper talvez acrescentasse que em epistemologia também não. Quero aqui argumentar que abordar o conhecimento à luz da evolução - algo que, a propósito, nem mesmo um Ernst Mayr conseguiu fazer em seu monumental The growth of biological thought (Mayr, 1982), apesar de ser um dos pilares do pensamento evolutivo darwiniano - permite-nos evitar tanto o anseio por fundamentos últimos de validação do conhecimento, peculiar ao projeto epistemológico do século xviı, quanto a insustentável demanda, comum ao recuo pragmatista, tão em voga nos dias atuais, e ao esforço kantiano-heideggeriano de "superar a epistemologia", de que todo corpo de conhecimento seja confinado ao seu próprio tempo-ou, em outras palavras, de que o passado se torne irrelevante para o presente.

Receio que o caminho que conduziu ao referido recuo pragmatista tenha sido aberto no século xvıII, por David Hume. Hume, como é sabido, combateu o anseio cartesiano por conhecimento apodítico postulando que não há conhecimento para além daquele que possa vir a resultar do hábito, irrefletido, de conectar experiências (passadas) a expectativas (futuras). Se todo conhecimento é um resultado da aquisição de certos hábitos (como o de esperar que a água sacie a sede, o sol reapareça pela manhã e nós permaneçamos os mesmos ao amanhecer), então tudo o que há para ser investigado a seu respeito é como nossas mentes precisam operar para que tal aquisição seja possível. Nessa perspectiva, falar sobre o conhecimento é o mesmo que falar sobre a natureza da mente humana, isto é, investigar como nossas mentes precisam ser para que possamos estar permanentemente tendo expectativas que nenhuma evidência ou raciocínio nos autoriza a ter.

Ao postular que nenhuma evidência ou raciocínio pode estabelecer uma conexão entre o passado e o futuro, Hume atingiu mais que o anseio cartesiano por certeza. Ele pôs em questão a própria viabilidade de qualquer projeto epistemológico concebível. Acredito que tal questionamento, apenas insinuado no século xvıII, reapareceu com força total no século xx, com uma roupagem behaviorista. Tal reaparecimento é visível na abordagem sociológica do conhecimento de Thomas Kuhn, ${ }^{3}$ no naturalismo holista de W. V. Quine ${ }^{4}$ e no pragmatismo wittgensteiniano de Richard Rorty, ${ }^{5}$ para citar apenas o que considero ser as variantes mais estimulantes da rejeição, de matriz

2 Dobzhansky (1973).

3 Veja-se Freitas (1998).

4 Veja-se Freitas (2004) e Freitas \& Collares (2001).

5 Veja-se Freitas (2000). 
humiana, da epistemologia. Em todos esses casos rege o princípio, ausente do empirismo cético de Hume, mas perfeitamente passível de ser remontado a ele, de que não há nada a ser dito a respeito do conhecimento além daquilo que uma descrição de comportamentos pode oferecer.

Paralelamente a essa rejeição, de matriz humiana, da epistemologia, assiste-se recentemente a uma rejeição cujos fundamentos são, algo surpreendentemente, buscados na filosofia transcendental de Kant. Refiro-me à proposta, de Charles Taylor, de "superar a epistemologia" a partir de um argumento cujo teor é basicamente o seguinte: o projeto epistemológico cartesiano assenta-se em um conjunto de noções antropológicas insustentáveis - especialmente, a de indivíduo desprendido. Explicitemos essas noções, que constituem a própria condição de possibilidade de qualquer epistemologia, e estaremos mostrando a inviabilidade de tal área de investigação. Eu suspeito que há uma enorme afinidade entre essa proposta e o projeto de Foucault, em As palavras e as coisas (Foucault, 1970), de "trazer à luz" as condições de possibilidade de nossas alegações de conhecimento. Taylor, entretanto, quer ir além de Foucault. Ele quer dar um passo que, embora necessário, Foucault não pôde se permitir dar, a saber, tornar possível a comparação entre alegações de conhecimento realizadas sob o domínio de tradições de pensamento, visões de mundo ou, para usar seu próprio termo, epistemes diferentes. Taylor, ao mesmo tempo em que pretende "superar a epistemologia”, admite a possibilidade de haver ganho real de conhecimento quando há transição de uma visão de mundo para outra, e de esse ganho poder ser avaliado racionalmente. Daí, ele se dá ao trabalho de mostrar como é possível avaliar, à margem de qualquer discussão de cunho epistemológico, o que se ganha, em termos cognitivos, com tais transições. Ele se deteve na transição da física aristotélica para a física moderna para argumentar que podemos entender melhor a fragilidade da primeira se ignorarmos os critérios, usualmente estabelecidos pelos epistemólogos, para adjudicar entre teorias. ${ }^{6}$

Minha principal objeção a esta linha de raciocínio é que ela decreta, de antemão, a impossibilidade de a física aristotélica ter qualquer relevância cognitiva para além do período em que dominou o cenário epistemológico - algo que, em princípio, ela poderia ter, apesar de sua óbvia fragilidade. ${ }^{7}$ Em termos mais gerais, a perspectiva de Taylor retém aquilo que considero ser a principal deficiência da visão pragmatista, a saber, tornar o que quer que ocorra em um tempo passado irrelevante para o que quer que venha a ocorrer em um tempo posterior, seja esse tempo posterior um passado menos remoto, o presente, ou mesmo o futuro. Assim, se Taylor, diferentemente de Foucault,

6 Taylor discute a maneira "não epistemológica" de mostrar a fragilidade do pensamento aristotélico em um capítulo intitulado "Explanation and practical reason" (Taylor, 1995).

7 Veja-se, por exemplo, o artigo de Elliot Sober: "Evolution, population thinking, and essentialism”, em Sober (1994). 
não se furtaria a discutir o que se ganhou com uma transição como, digamos, a do "instrucionismo" de um Lamarck para o "selecionismo" de um Darwin, sua abordagem, não obstante, confinaria, de antemão, a relevância cognitiva do pensamento lamarckiano ao século xviıI.

Embora não faça objeção à proposta de levar adiante o projeto foucaultiano de "trazer à luz" as condições de possibilidade de nossas alegações de conhecimento (e as de nossos antepassados), penso que essa proposta só pode gerar frutos se não implicar, de antemão, um aprisionamento das alegações de conhecimento em seu próprio tempo. É nesse ponto que Darwin, via Popper, entra. Seu pensamento evolutivo pode nos ajudar a responder perguntas que tanto Taylor quanto os herdeiros do empirismo cético de Hume estão impedidos sequer de conceber. Refiro-me a perguntas como: Por que não devemos aprisionar o pensamento científico de um Aristóteles na Idade Média, ou, digamos, o de um Cuvier no século xvııı? Por que deveríamos ver tais pensamentos (ou qualquer pensamento do passado) como muito mais que meras relíquias?

Em linhas gerais, minha resposta é a seguinte. O pensamento científico de um Aristóteles, ou de um Cuvier, como, de resto, qualquer pensamento dito científico, consiste de um conjunto de proposições teóricas, que podem se revelar verdadeiras ou falsas, acrescido do conjunto não explicitado de concepções metateóricas (ou, mesmo, metafísicas), a salvo da ação do modus tollens, que constituem "o pano de fundo" dessas proposições. Esses dois conjuntos se articulam em um único bloco. Quando um determinado bloco desmorona - a título de exemplo, o "bloco" aristotélico desmoronou no século XVII; o "bloco" representado pelo pensamento criacionista de Cuvier desmoronou nos século xix - é possível que uma ou outra de suas partes, isto é, algumas das referidas concepções metateóricas e uma ou outra proposição teórica que tenha porventura resistido à ação do modus tollens, se desprenda e venha, posteriormente, a se acomodar em algum outro lugar. Um resultado possível de tal acomodação de fragmentos desprendidos é o desencadeamento de mudanças evolutivas - aqui entendidas, à Popper, como a emergência de novos problemas.

Assim, se se toma algo como o campo da Inteligência Artificial aplicada à Medicina (IAM) como exemplo, um dos "blocos" sobre os quais esse campo se sustenta desde os anos 1980 é o chamado Raciocínio Categórico - em oposição ao chamado raciocínio bayesiano, de caráter probabilístico. Esse "bloco" consiste de um conjunto articulado de pressupostos e de teorias sobre como tornar o computador capaz de fazer inferências simbólicas - como, por exemplo, a de que olhos amarelados são um sinal de icterícia - e, a partir daí, seguir uma linha de raciocínio. Em um trabalho anterior (Freitas, 2003, cap. 6) procurei mostrar como o Raciocínio Categórico evoluiu em razão de alojar dois fragmentos externos, a saber, em um primeiro momento, o pressuposto de que uma causa só age sobre o que lhe é contíguo no tempo e no espaço (esse 
pressuposto é conhecido como a idéia de causalidade local) e, em um segundo, a teoria de que a excreção da digitalis se faz pelos rins. O primeiro fragmento, uma vez alojado, levantou o problema de como evitar lacunas causais na representação de relações entre doenças e sintomas, ${ }^{\mathbf{8}}$ o qual, por sua vez, desencadeou todo um conjunto de novos problemas, de como mesclar os raciocínios probabilístico e determinístico a como representar a influência que diferentes doenças exercem umas sobre as outras. $\mathrm{Na}$ medida em que tais problemas foram postos, esforços no sentido de resolvê-los deram lugar a uma nova teoria de decisão médica assistida por computador e, em decorrência, ao desenvolvimento de um modelo mais aprimorado de representação do conhecimento médico. A idéia de causalidade local agiu, assim, como um trigger, isto é, ela desencadeou todo um conjunto de revisões dentro de um determinado "bloco" (o Raciocínio Categórico), dando desta forma lugar à proliferação de novos problemas e de novas teorias na área de Inteligência Artificial. Pode-se dizer que ao alojar a idéia de causalidade local, o chamado Raciocínio Categórico tornou-se mais abrangente e mais "ventilado", isto é, mais apto a alojar outros fragmentos desprendidos, oriundos de outros "blocos" e, portanto, a desenvolver novos modelos e/ou teorias. Dentre esses outros fragmentos, destacou-se, conforme já mencionei, a teoria de que a excreção da digitalis se faz pelos rins. Esta se alojou no Raciocínio Categórico e desencadeou todo um conjunto de novos problemas - como, por exemplo, o de tornar o computador capaz de determinar os efeitos anteriores do uso do medicamento em um paciente específico.

Assim, tanto a idéia de causalidade local quanto a teoria de que a excreção da digitalis se faz pelos rins (essas partes desprendidas de "blocos", que se alojaram em um outro "bloco") podem ser vistas como fontes de variações potencialmente evolutivas nas tradições ou sistemas de pensamento em que vieram a se alojar, da mesma forma que uma mutação genética é uma fonte de variação, potencialmente evolutiva, nos organismos biológicos que abrigam o gene mutante.

A própria possibilidade de tal discussão estaria, entretanto, excluída de antemão se nos alinhássemos quer à versão humiana, quer à versão heideggeriana-kantiana de rejeição da epistemologia. Com efeito, enquanto os primeiros simplesmente nos proíbem de tentar dizer qualquer coisa sobre o interesse (ou, se se preferir, a falta de

8 Talvez o exemplo seguinte ajude a entender o que seja "evitar lacunas causais". É sabido que diarréia causa desidratação. Cabe à IAM “ensinar” isso ao computador. Para tanto, o computador precisa "aprender” os mecanismos por meio dos quais a diarréia conduz à desidratação. Evitar "lacunas causais” é tornar o computador capaz de operar com o maior número de mecanismos possíveis. É torná-lo capaz de acompanhar a seguinte linha de raciocínio: diarréia conduz à perda do fluxo gastrintestinal. Expresso num nível de detalhe seguinte, perda do fluxo gastrintestinal pode ser descrito como consistindo da perda de sódio e de potássio em conjunto com outros eletrólitos. A perda de água na presença de quantidade reduzida de sódio extracelular resulta em volume extracelular baixo o qual, no nível mais alto de descrição, é descrito como desidratação. 
interesse) científico de qualquer sistema de pensamento - digamos, do pensamento aristotélico - e os últimos querem nos ensinar a constatar a fragilidade desse pensamento, convidando-nos a ver quão incapaz ele é, se comparado ao pensamento racionalista moderno, de perceber claramente os pressupostos que lhe dão sustentação, Darwin, cuja perspectiva nos permite compatibilizar o reconhecimento do fracasso do projeto fundacional do século xvı com uma esperança de manter a epistemologia viva - isto é, de haver ainda coisas importantes a serem ditas a respeito do conhecimento para além daquilo que possa ser oferecido, seja por uma descrição de comportamentos, seja por um esforço de "trazer à luz" as premissas que estão na raiz de nossas alegações de conhecimento - nos convidaria a identificar fragmentos que tenham vindo a se destacar do sistema de pensamento em consideração e a se articular, em um momento posterior, a outros fragmentos, oriundos de qualquer outro lugar, de forma a desencadear a emergência de problemas novos - e, portanto, mudanças evolutivas em corpos já existentes de conhecimento.

É justamente esse tipo de exercício, o de mostrar a importância científica de um sistema de pensamento do passado, por mais bizarro que possa parecer aos nossos olhos, reconstituindo a trajetória de fragmentos que tenham se destacado de tal sistema de forma a viabilizar a emergência de algum problema novo, que a abordagem evolutiva do conhecimento convida-nos a fazer.

Meu exemplo anterior contempla esse ponto apenas parcialmente. Digo parcialmente porque os dois fragmentos migratórios que mencionei, embora sejam responsáveis pelo desencadeamento de mudanças evolutivas em um corpus determinado de conhecimento, não são oriundos de "blocos" já demolidos. Mas fragmentos de "blocos" já demolidos podem desempenhar igualmente bem esse papel. Considere-se, por exemplo, o problema em torno do qual o próprio pensamento biológico passou a se mover nas últimas duas décadas: compreender como a ontogenia e a filogenia se articulam no processo evolutivo. ${ }^{9}$ Como pôde esse problema emergir? Eis o que estaremos, de antemão, impedidos de investigar se rejeitarmos a epistemologia quer via Hume, quer via o Kant de Taylor porque, em ambos os casos, seremos levados a aprisionar os pensamentos do já citado Cuvier (1769-1832) e de Aristóteles no tempo.

Receio que as raízes do referido problema podem ser encontradas em algo que seria, nos dias de hoje, alvo da mais impiedosa zombaria: o chamado "catastrofismo" de Cuvier. Em pleno século xviıI, quando naturalistas como Buffon (1707-1788) e Lamarck $\left(1744^{-1829}\right)$ já acenavam com um pensamento evolutivo, ${ }^{10}$ Cuvier insistia

9 Veja-se, dentre outros, Thompson (1988), Smith (1998) e Raff (1996).

10 Veja-se, a respeito, Hull (1967) e Mayr (1982). 
em afirmar que as espécies eram fixas e só podiam ser criadas e extintas de um único golpe (via catástrofes naturais). ${ }^{\mathbf{1 1}}$ Isso levou os historiadores (ditos "tradicionais") da ciência a opor Guvier (cuja perspectiva era criacionista) a Lamarck e Darwin. Foucault protesta. Para ele, essa é uma maneira muito superficial de ver as coisas. É verdade que Cuvier tinha uma visão "fixista” da espécie. Também é verdade que Lamarck e Darwin partilhavam uma visão evolutiva da espécie. Mas disto, argumenta Foucault, não se segue que o pensamento de Darwin estivesse mais próximo do de Lamarck do que do de Cuvier. E, muito menos, que Lamarck e Darwin estivessem do lado da verdade e Cuvier do lado do erro. Basta, continua Foucault, examinarmos a "grade" epistemológica que está na raiz das alegações dos referidos naturalistas para concluirmos que o pensamento de Cuvier, a despeito de envolver uma concepção “fixista”, está bem mais próximo do pensamento evolutivo de Darwin do que o pensamento de Lamarck. ${ }^{\mathbf{1 2}}$

Mesmo admitindo que Foucault tenha razão, ele falha por manter, ainda que involuntariamente, o "catastrofismo" de Cuvier preso ao século xviı. Foucault, não obstante seu louvável e bem sucedido esforço para salvar Cuvier da pecha de obscurantista, mantém o pensamento deste último irrelevante para qualquer período posterior ao século xviı - o máximo que Foucault concede ao pensamento de Cuvier é a posição de "relé" do pensamento evolutivo darwiniano. ${ }^{\mathbf{1}} \mathrm{O}$ custo de tal aprisionamento, quero sugerir, é justamente o de inviabilizar o entendimento do processo que culminou na emergência do problema que hoje move o pensamento biológico.

Para mostrar que o "catastrofismo" de Cuvier, este formidável edifício metafísico que ruiu em bloco no século xIx, cumpre um papel relevante no referido processo, seria necessário identificar algum fragmento que tenha se desprendido deste edifício e, em algum momento posterior, se articulado a outros fragmentos, oriundos de outros "edifícios" demolidos, ou, alternativamente, se acomodado em algum outro "edifício" já estabelecido, de forma a desencadear mudanças que pudessem culminar na emergência do problema em consideração. Suspeito que a obra monumental de Cassirer possa nos conduzir a tal fragmento. ${ }^{14}$ Trata-se da noção de plano de construção - idéia de que cada tipo de animal, sejam os vertebrados ou os moluscos, os articulados ou os radiados, descansa sobre um plano de organização próprio e peculiar a ele. Minha hipótese é que esta noção está na raiz da indagação atual sobre o papel evolutivo do desenvolvimento

11 Veja-se, a respeito, Haeckel, 1911, p. 45. A propósito, Haeckel elogia Lamarck por não se deixar influenciar pelo catastrofismo de Cuvier.

12 Veja-se Foucault, 1970, Capítulos 5 e 8.

13 Veja-se, a respeito, a conferência de Foucault, "A posição de Cuvier na história da biologia”, em Mota, 2000.

14 Cassirer (1948). 
ontogenético - e, portanto, do problema de como a filogenia (descendência genética) e a ontogenia (desenvolvimento do embrião) se articulam no processo evolutivo.

Há, entretanto, uma pedra no meio do caminho. Tal indagação, pode-se legitimamente objetar, não é nova. Na verdade, ela data da segunda metade do século xIx. Mal havia Darwin publicado A origem das espécies, em 1859, e o morfologista alemão Ernst Haeckel (1834-1919) já se mobilizava para compreender o papel evolutivo do desenvolvimento ontogenético. Ora, Haeckel conhecia, como poucos, o pensamento de Cuvier, e jamais lhe ocorreria aproveitar qualquer coisa do "catastrofismo". Se, continuaria a objeção, nem no século xIx a noção de "plano de construção" pôde ter alguma relação com a emergência da indagação sobre o papel evolutivo do desenvolvimento ontogenético, por que ela o teria agora, quando soa ainda mais bizarra?

Minha resposta é que, se por ocasião da crítica de Haeckel, a referida noção se resumia a uma bizarra peça de museu, era sobretudo em razão de se achar, então, "flutuando" livremente, sem se articular a nada. Em outras palavras, era apenas em razão de ter se desprendido do edifício catastrofista sem ter, em contrapartida, se juntado a alguma(s) outra(s) noção(ões). Se, entretanto, em algum momento posterior, tal viesse a ocorrer, então seria perfeitamente possível que ela deixasse de ser uma mera relíquia e viesse a desencadear mudanças evolutivas em algum corpo de conhecimento estabelecido. Conjecturo que foi isto o que ocorreu. Valho-me, uma vez mais, de Cassirer. Este acompanhou a trajetória da referida noção até, pelo menos, um século mais tarde, quando esta se articulou ao "vitalismo sem força vital", de Uexküll, cuja conexão com a indagação sobre o papel evolutivo do desenvolvimento ontogenético parece-me bastante evidente. A perspectiva evolutiva de Darwin-Popper, então, ao invés de confinar a noção de "plano de construção" ao século xvıII, convidar-nos-ia a reconstruir a trajetória dessa noção a partir do ponto em que Cassirer parou.

A proposta de não confinar o pensamento de um Cuvier ao século xviır pode, na verdade, ser vista como um caso especial de uma proposta mais geral: a de não confinar a concepção tipológica, pré-darwiniana, de espécie ao século xix. Convencionalmente se afirma que o advento do darwinismo e, mais especificamente, da síntese evolutiva dos anos 1930, enterrou de vez um dos maiores obstáculos para o avanço do conhecimento biológico: a concepção tipológica da espécie, segundo a qual há algo inerente aos indivíduos de uma mesma espécie que faz de cada qual o que é. De acordo com esse raciocínio, da mesma forma que é impossível entender o que foi a revolução científica do século xviı sem entender o que foi o sistema metafísico aristotélico que Galileu derrubou, também é impossível entender o que foi a referida síntese evolutiva - que, por assim dizer, salvou a tradição darwiniana da extinção - sem entender o que foi o sistema metafísico que a mesma derrubou, a saber, o pensamento tipológico subjacente à chamada "morfologia idealista" do século xIX. 
Embora eu não tenha objeção a tal raciocínio, não se pode perder de vista (como seríamos levados a fazer se rejeitássemos a epistemologia à Hume ou à moda do Kant de Taylor) que, da mesma forma que a revolução einsteiniana recuperou determinadas concepções oriundas da cosmologia aristotélica que Galileu havia deixado para trás, ${ }^{\mathbf{1 5}}$ busca-se agora, na biologia, uma "nova síntese" que recupere algumas das concepções oriundas do pensamento tipológico que a síntese evolutiva deixou para trás, notadamente as noções de homologia de Richard Owen (o grande adversário de Darwin) e de campo morfogenético, esta última herdada da embriologia de matriz vitalista (ela própria mais um desdobramento do pensamento tipológico), dos anos 20. Busca-se, através da recuperação dessas noções, tornar a biologia capaz de cumprir uma promessa que, supostamente, a síntese evolutiva não pôde torná-la capaz de cumprir, a saber, explicar a macro-evolução, isto é, a formação de espécies de categorias mais elevadas a partir de espécies de categorias mais baixas - a formação, por exemplo, de um anfíbio a partir de um peixe, ou de alguma ave a partir de algum réptil. ${ }^{\mathbf{6}}$

Há uma considerável literatura procurando mostrar como a tradição darwiniana pode (e deve) incorporar as referidas concepções para não estacionar. ${ }^{17}$ Mas isto envolve o sério problema de como tornar a tradição darwiniana compatível com concepções herdadas da visão tipológica - principalmente com a concepção essencialista de espécie que esta visão pressupõe. Espécies, em uma visão estritamente darwiniana, não são, como no pensamento tipológico, classes naturais. Elas são apenas o resultado da precária estabilização de fundos de genes determinados. Esta concepção estatística de espécie viabilizou os trabalhos pioneiros de genética das populações de Fisher, Haldane, Wright (e, posteriormente, de Dobzhansky) e, nos anos 4,o, os trabalhos clássicos sobre a formação de novas espécies de Mayr e do paleontologista George Simpson. Mas não solucionou o problema de explicar processos macro-evolutivos a partir de processos micro-evolutivos - para o qual o pensamento tipológico, bem ou mal, tem uma resposta (a resposta "saltacionista"). Como pode a tradição darwiniana se mover em relação a este problema se não puder contar com a ajuda das concepções metafísicas oriundas do pensamento tipológico (rejeitadas nos anos 3o)? Até onde posso perceber, este é o grande impasse que a tradição darwiniana enfrenta atualmente. Se seguirmos as recomendações anti-epistemológicas de Taylor, ou as de matriz humiana, seremos, entretanto, levados a perder esse ponto.

15 Veja-se, a respeito, o esplêndido artigo de Alexandre Koyré, "Da influência das concepções filosóficas sobre a evolução das teorias científicas”, em Koyré, 1991, publicado originalmente em 1955.

16 Veja-se, a respeito, Gilbert; Opitz \& Raff, 1996.

17 Veja-se referências citadas nas notas 9 e 16. 
Talvez devamos à obra monumental do já citado biólogo alemão Ernst Mayr, The growth of biological thought, de 1982, o conhecimento de que seria inconcebível qualquer síntese entre a genética mendeliana e a teoria da evolução por seleção natural se a concepção tipológica de espécie, que prevalecera no século xıx e nas primeiras décadas do século xx, não tivesse sido abandonada em favor de uma concepção populacional de espécie. Enquanto tal substituição não ocorreu, a descoberta das leis de Mendel foi um enorme obstáculo, e não uma condição primordial, para o avanço da teoria darwiniana da evolução. Em outras palavras, para que as leis de Mendel e a teoria darwiniana da evolução pudessem se fundir na "síntese evolutiva", foi necessário que espécies passassem a ser vistas, não mais como a atualização ou a realização de tipos morfológicos pré-determinados (como na visão tipológica), mas, em radical contraste, como meras populações ou agregados altamente diversificados de indivíduos geneticamente únicos. Sem esta concepção de espécie como um agregado instável de indivíduos geneticamente únicos que partilham um fundo comum de genes a idéia de seleção natural não faz qualquer sentido, e esta concepção não estava disponível até a década de vinte. Daí que, nas primeiras décadas do século xx, o pensamento biológico era marcadamente anti-selecionista.

Dificilmente alguém discordaria de tudo isto nos dias de hoje. Mas, disto decorreria que o pensamento tipológico deve, de saída, ser confinado ao século xix e ao início do século xx? A resposta de Mayr é um inequívoco sim. ${ }^{\mathbf{1 8}}$ Ele parece ter pensado, em curiosa e involuntária sintonia com todos os esforços contemporâneos de "superar a epistemologia", que, dado que a concepção tipológica de espécie subjacente à morfologia idealista do século xıx é insustentável, então esta morfologia não pode ter qualquer relevância para além de seu tempo. Em decorrência, ele deteve-se nos primeiros mendelianos anti-selecionistas (de Vries, Bateson e Goldschmidt) e nos morfologistas idealistas do século xıx, notadamente em Owen, Saint-Hilaire e Cuvier, e não vislumbrou a possibilidade de haver uma continuidade entre as concepções metafísicas desses morfologistas e, por exemplo, a importante descoberta de Hans Spemann, nos anos 20, de que uma parte do embrião exerce influência sobre o desenvolvimento de uma parte vizinha. ${ }^{19}$ Na verdade, um embriologista da estatura de Spemann sequer aparece no índice remissivo do livro (de 974 páginas) de Mayr. Ele mereceu de Mayr apenas

18 Por outro lado, a resposta de Sober (1994) é um inequívoco não. Sober vai longe a ponto de sugerir que o modelo aristotélico do estado natural, que está na base do pensamento tipológico, "is not wholly without a home in contemporary biology; in fact, the way in which it finds an application there highlights some salient facts about what population thinking amounts to" (p. 204).

19 Os estudos pioneiros de Hans Spemann sobre desenvolvimento embrionário mereceram a atenção de uma vasta literatura. Limito-me a citar Waddington, G. H. "Fields and gradients", in Locke (org.), 1966. 
uma brevíssima repreensão pelo teor tipológico de seu pensamento, e verdadeiros gigantes da embriologia do século xx como Paul Weiss, de Beer e Waddington não mereceram qualquer menção, nem mesmo a breve repreensão dirigida a Spemann.

Duvido muito que exista algum historiador da ciência que esteja a salvo da acusação de ter negligenciado algum nome importante. Mas, na medida em que, já de saída, confinamos algum pensamento a seu próprio tempo, somos levados a negligenciar não apenas um ou outro nome, mas inteiros programas de pesquisa. Foi o que aconteceu no caso de Mayr. Ele foi levado a desconsiderar toda a tradição da "morfologia racional", que viveu seu esplendor nos anos 20, foi timidamente retomada nos anos 60 e, nos anos 80, veio a culminar no que é hoje conhecido como Biologia do Desenvolvimento - isto é, o estudo da relação entre o desenvolvimento embrionário e a evolução.

Suspeito que o livro Embryos, genes and evolution, de Rudolf Raff \& Thomas Kaufman (1983), é um dos marcos de fundação deste esforço recente no sentido de explicar a mudança evolutiva não só em termos genéticos mas, também, em termos dos padrões de desenvolvimento embrionário.

Tendo publicado seu livro em 1982, Mayr não poderia ter citado o livro de Raff e Kaufman, de 1983. Não obstante, ele poderia ter dado alguma informação que nos pudesse ajudar a entender como o pensamento de um de Beer, ou de um Spemann, ambos da década de 20, puderam encontrar terreno para prosperar nos anos 80. Há uma curiosa ironia aqui. Mayr é um ferrenho adversário do saltacionismo em biologia - isto é, da idéia, que remonta aos primeiros mendelianos anteriormente citados, de que novas espécies surgem por acaso, de forma abrupta. A famosa tese do "monstro promissor", de Goldschmidt, é a mais perfeita tradução da visão saltacionista. Mayr notabilizou-se por seus argumentos contra Goldschmidt, isto é, por mostrar o caráter contínuo e gradual da formação de novas espécies. Não obstante, seu silêncio sobre os citados embriologistas dos anos 20 não deixa de encerrar uma epistemologia saltacionista, isto é, a premissa de que foi por um salto, por uma obra do acaso, que o pensamento tipológico do século xix foi reabilitado quase um século depois. Nesse caso, nada teria preparado o terreno para que tal reabilitação pudesse ocorrer e render frutos. Não posso, de saída, descartar a possibilidade de simplesmente ter havido este salto, mas também não posso, sem mais, subscrever a epistemologia saltacionista subjacente ao pensamento de Mayr. Deve-se, portanto, procurar entender como foi preparado o terreno para que a morfologia racional dos anos 20 , que remonta ao pensamento tipológico do século xıx e, mais remotamente, às noções aristotélicas de "unidade do plano" e "homologia", pudesse ser revivida e, mais importante, incorporada pela tradição darwiniana no final do século xx.

Em face do exposto, devo concluir dizendo que procurei indicar nesse texto uma agenda de questões que seremos, de antemão, impedidos de encarar se, ao invés de 
tentarmos substituir o projeto epistemológico fundacional do século xviı por outro, de cunho evolutivo, contentarmo-nos em decretar, de antemão, como se tem feito correntemente, a inviabilidade de qualquer projeto epistemológico concebível.

\title{
Renan Springer de Freitas
}

Professor Doutor do Departamento de Sociologia e Antropologia da Universidade Federal de Minas Gerais. springer@ciclope.lcc.ufmg.br

\begin{abstract}
ABSTRAGT
The collapse of the modern foundational epistemological project has led some authors to claim that epistemology is dead. There has been either a retreat to a pragmatic approach to knowledge, according to which there is nothing to be said about knowledge except what can result from an investigation of the ways in which certain beliefs are formed, or a Kantian- and Heideggerian-inspired attempt to "overcome epistemology" by "bringing into light" the untenable anthropological premises that underlie the Cartesian failed quest for apodictic knowledge. It has hardly been noticed, however, that Popper pioneered all this discussion about the feasibility of the modern epistemological project without thereby concluding that any conceivable epistemological project is necessarily doomed to failure. He envisaged a solution in Darwin's evolutionary thought. I argue that by making sense of knowledge in the light of evolution one can avoid both the modern anxiety for apodictic knowledge, and the untenable requirement, which in fact underlies both the pragmatic and the Kantian-Heideggerian rejection of foundational epistemology, that every piece of knowledge be encapsulated in its own time - in other words, that the past becomes irrelevant for the present.
\end{abstract}

KEYWoRds • Foundational epistemology. Pragmatic retreat. Evolutionary thought.

\section{REFERÊNGIAS BIBLIOGRÁFICAS}

Bayes, K.; Boham, J. \& MacCarthy, T. (Orgs.). After philosophy. Cambridge (Mass.), MIT Press, 1987. Cassirer, E. El problema del conocimiento. México, Fondo de Cultura Económica, 194.8. v. 4, Livro 2.

Dobzhansky, T. Nothing in biology makes sense except in the light of evolution. American Biology Teacher, 35, p. 125-9, may, 1973. Disponível em: <http://www.pbs.org/wgbh/evolution/library/10/2/ l_102_01.html> ou: 〈http://www.2think.org/dobzhansky.shtml>

Foucault, M. The order of things. Londres, Tavistock Publications, 1970.

Freitas, R. S. de. Desnaturalizando Kuhn. Estudos Avançados, 33, 12, p. 185-96, $199^{8}$. . A desforra de Hume. Revista Brasileira de Ciências Sociais, 42, 15, p. 23-38, 2000. Sociologia do conhecimento, pragmatismo e pensamento evolutivo. Bauru, EDUSC, 2003. . A saga do ideal de boa ciência. Revista Brasileira de Ciências Sociais, 55, 19, p. 91-105, 2004.

Freitas, R. S. de. \& Coldares, A. C. O modus tollens, o holismo de Duhem-Quine e as ciências sociais. Dados, 44, 2, p. 397-4,26, 2001. 
Gilbert, S. F.; Opitz, J. M. \& RafF, R. A. Resynthesizing evolutionary and developmental biology. Developmental Biology, 173, p. 357-72, 1996.

HaEckel, E. Historia da creação natural. Porto, Livraria Chardro Editora, 1911.

Hull, D. The metaphysics of evolution. The British Journal for the History of Science, 3, 12, p. 3०9-37, 1967. Koyré, A. Estudos de história do pensamento filosófico. Rio de Janeiro, Forense Universitária, 1991.

Locke, M. (Org.). Major problems in developmental biology. Nova Iorque, Academic Press, 1966.

MaYr, E. The growth of biological thought. Cambridge (Mass.), Belknap Press, 1982.

MoтA, M. B. da. (Org.). Ditos \& escritos II: Foucault, arqueologia das ciências e história dos sistemas de pensamento. Rio de Janeiro, Forense Universitária, 2000.

RAFF, R. The shape of life: genes, development and the evolution of animal form. Chicago, University of Chicago Press, 1996.

RafF, R. \& Kaufman, T. Embryos, genes and evolution. Nova Iorque, Macmillan, 1983.

Sовев, E. From a biological point of view: essays in evolutionary philosophy. Cambridge, Cambridge University Press, 1994.

Sмітн, J. M. Shaping life: genes, embryos and evolution. New Haven, Yale University Press, 1998.

TAYlor, C. Philosophical arguments. Cambridge (Mass.), Harvard University Press, 1995.

Thompson, K. S. Morphogenesis and evolution. Nova Iorque, Oxford University Press, 1988. 